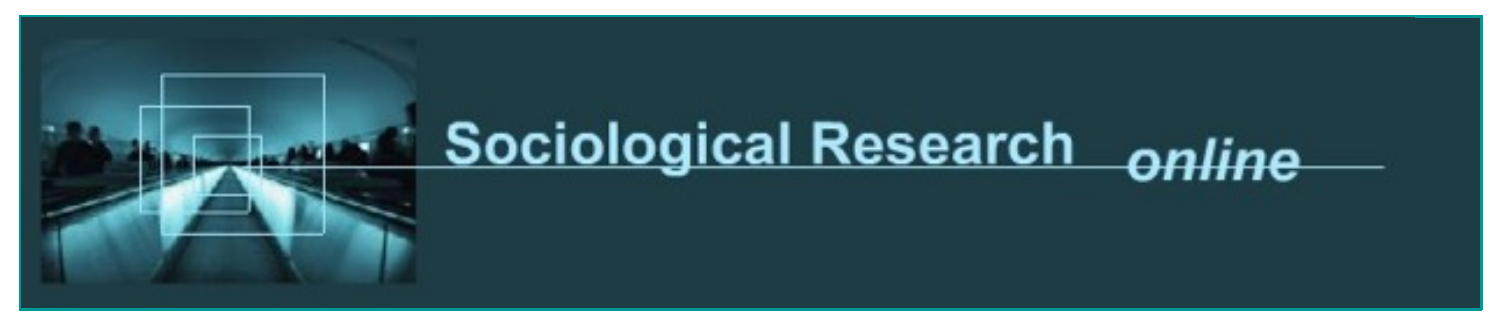

\title{
Power and Resistance: A Case Study of Satire on the Internet
}

\author{
by Lijun Tang and Syamantak Bhattacharya \\ Cardiff University; University of Plymouth \\ Sociological Research Online, 16 (2) 11 \\ <http://www. socresonline.org.uk/16/2/11.htm/> \\ $10.5153 /$ sro. 2375
}

Received: 26 Jan 2011 Accepted: 17 May 2011 Published: 31 May 2011

\begin{abstract}
Past studies on print and TV satire have revealed that satire can be seen as a site of resistance to power. In light of this, interesting questions can be raised regarding Internet satire: what does the Internet contribute to the resistance and what kind of power relation is played out on this site? Using an example from China, this paper reveals that like its print and TV counterparts, Internet satire reflects a widespread feeling of powerlessness, rather than offering the general public any political power. However, the Internet helps to push the symbolic power of satire to a higher level. This is because it makes satire a tool for the grassroots which facilitates the creation and spread of satirical ideas, and also helps to release and stimulate the enormous reserve of public wit and wisdom. As a result, satire on the Internet has the potential to generate a chain of related satirical work, which can create a satire movement and subject power to sustained shame and ridicule.
\end{abstract}

\section{Keywords: CCTV, China, Empowerment, Internet Control, Internet Incident, Online Activism, Subversion, Symbolic Power}

\section{Introduction}

1.1 Throughout its long history, satire has been an interesting subject stimulating discussions and debates. This is not only because it is a form of art, but perhaps more importantly because it playfully serves as a social critique, exposing and attacking social folly. It is not surprising then that a large body of literature has been generated examining historical and/or contemporary satire (e.g.Boler 2006; Fletcher 1987; LeBoeuf 2007; Meikle 2008). The primary focus of this body of literature has been on print and TV satire, which is monopolised by professional satirists. The Internet technology, however, has liberated satire from the monopoly of professionals and has enabled ordinary people, or netizens, to create and disseminate satirical work online (Berthon et al. 2008). This development calls for close examinations of satire on the Internet.

1.2 One insight from previous studies about classic satire, as shown in the next section, has been that it is a site where stories of resistance and domination are written. In light of this, some interesting questions can be raised with regard to satire on the Internet: what does the Internet contribute to the resistance and what kind of power relation is played out on this site? This paper looks into these questions using an example from China. Situated at the intersection between the Internet, satire, and power, the aimed contribution of the paper is three fold. First, it reveals the new possibilities of satire enabled by the Internet; secondly, it explores the empowerment potentials of the Internet through the lens of satire; and thirdly, it sheds light to the shift (however small it is) of power dynamics in China in the Internet era.

\section{Satire and its duality}

2.1 Satire is an elusive term and difficult to define. As Connery and Combe (1995: 9) point out, it 'remains less an identifiable genre than a mode, and an astonishingly wide range of vastly varied works have been placed under its rubric'. Nevertheless, it is generally accepted that satire is a form of art as well as a critique which exposes, ridicules, and criticises human and social vices, follies, and shortcomings by use of parody, irony, travesty, and grotesquery (Boler 2006; Fletcher 1987; LeBoeuf 2007).

2.2 By combining its two essential components - attack and wit, satire brings about pleasure and appeals to audience. According to Griffin (1994), satirical pleasure is derived from several aspects. Like other literary forms, satire is about representation, although it specialises in representation of deformity. Such representation offers intellectual satisfaction as it demonstrates our ability to understand and control the world, and at the same time gratifies our sense of superiority by exposing others' shortcomings. More importantly, satire amplifies folly and makes its absurdity prominent by means of reduction (reducing irrelevant details to minimum) and exaggeration (enlarging and exaggerating defect features). Such treatment of folly simultaneously produces two effects: it excites people by arousing them emotionally; it pleases them by providing means to launch a symbolic attack which helps to discharge aroused and/or long-suppressed anger. Thus, it is both exciting and cathartic. Releasing anger by attacking vice in turn brings about a sense of triumph.

2.3 Maybe because satire entertains, Griffin (1994) suggests that one dimension of it can be understood as 'rhetoric of display and play'. Satirists play with words and ideas and enjoy it. Perhaps they enjoy 
displaying their brilliant wit even more, since it wins them the admiration and applause of the audience and thus brings about glory. Satire entertains by attacking. While in some cases mundane entertainment can be the major purpose of satire, in other cases socio-political criticism is the main focus. The latter reveals to Griffin (1994) another dimension of satire - 'rhetoric of inquiry and provocation'. It raises and explores questions as an attempt to seek truth; and by raising questions, it provokes the audience to doubt and demolish foolish certainties. As such, Meikle (2008: 6) argues that satire and media studies share certain similarities, - 'both ask questions about power and influence; both make judgements about social, cultural and political standards and failings; both are forms of cultural criticism'.

2.4 George Orwell (1945) once famously expressed, "every joke is a tiny revolution' because 'it upsets the established order', but does it change the order and thus have an impact on politics and society? This is one question that interests and engages scholars from different disciplines. Evidence suggests that in its long history, satire has hardly produced any tangible effect on the material world and practical politics (Elliot 1960; Griffin 1994). For Griffin (1994: 156), when aiming for socio-political criticism, what satire offers is a sense of 'moral victory' - by making a laughing stock of an enemy, it induces in its readers as well as in the satirists a sentiment of 'superiority in morality or in wit or in power'. This victory serves to compensate for the sense of powerlessness felt by political underdogs. As such, Griffin suggests that satire can be seen as a 'safety valve' - it allows underdogs to vent their discontents and prevents the pentup complaints from exploding. This comment resonates with Speier's opinion on whispered jokes. In discussing wit and politics, Speier (1998: 1395) points out: 'Indeed, throughout the history, whispered jokes have been safety valves ... [They] serve as a psychological alibi. By occasionally telling or laughing at a subversive jest, one can live more easily with nagging, half-conscious insights about accommodation or one's own failure to revolt.' He observes: where real revolt starts, jokes disappear. Jokes can be seen as a form of satire, and thus Speier's observation can be extended - the powerful, who can effect reform, do not do so using satire.

2.5 This is not to say that satire has no power. It is widely accepted to be subversive: it often raises questions, provokes doubts, and draws attention to social problems. In this context, Boler (2006) argues that satire 'speaks truth to power' and challenges the powerful. Similarly, Connery and Combe (1995: 11) point out that satire is potentially 'a site of resistance to cultural and political hegemony'. According to Griffin (1994), although its subversion may not be at a practical level, it nevertheless embodies an intellectual subversion. It spreads subversive ideas, and ideas, with little doubt, bear power. Such form of power can be aptly described as 'symbolic power' (Bourdieu 1991; Thompson 1995), which conceptualises the capacity of ideas and knowledge in shaping people's minds as they make people see and believe certain perspectives of the world rather than others. The ability to shape people's minds is undoubtedly important, as Castells (2007: 238) comments:

The fundamental battle being fought in society is the battle over the minds of the people. The way people think determines the fate of norms and values on which societies are constructed. While coercion and fear are critical sources for imposing the will of the dominants over the dominated, few institutional systems can last long if they are predominantly based on sheer repression.'

2.6 The above discussion suggests that when launching socio-political attacks, satire tends to have dual and even paradoxical qualities. It is playful and at the same time critical; it marks symbolic power, and yet reflects political powerlessness; it resists cultural and political hegemony, and yet unwittingly and ironically serves to make people resign to the latter's domination.

\section{Internet use in China}

3.1 One major issue dominating the discussion about Internet use in China has been democratisation: will the Internet bring about democracy? (Meng 2010). Since China is still an authoritarian state with no sign of democracy, research driven by this question is quite naturally led to the conclusion that the Internet is tightly controlled in China (Chase and Mulvenon 2002; Kalathil and Boas 2003; Kluver and Banerjee 2005; MacKinnon 2008; Walton 2001; Wang and Hong 2009). After all, according to the Open Net Initiative (2009), China has one of the largest and most sophisticated filtering systems in the world to block websites and web content that disseminate politically sensitive issues. Furthermore, Tsui (2003) argues that through state regulation, surveillance technology, economic incentives, and punitive action the authorities have made the Internet a panopticon which forces Chinese Internet users to exert selfcensorship and self-regulation. It is often argued that the tight control and censorship applied to Internet use serves to kill Chinese netizens' interest in discussing political issues and to divert their attention more towards online entertainment (Li 2010; MacKinnon 2008; Wang and Hong 2009).

3.2 However, if we change the question to, 'in what ways the Internet brings about empowerment in China?', we can see that as an alternative media the Internet provides the ordinary Chinese with a space to make their concerns visible. In China injustice, government officials' abuse of power, corruption and the associated conflicts between government agents/officials and ordinary people are burning social issues. However, conventional media primarily serve the interest of the authority, rather than that of the general public, in China. This is because they are owned and run by the governments. Prior to the economic reform in the early 1980s, media were state propaganda apparatus in charge of disseminating government policies, decisions and actions to the general public (Rawnsley 2006; Shen et al. 2009; Tong 2009), and allowing no negative reporting (de Burgh 2003). Although the economic reform has brought about media marketisation (Wang 2009; Weber and Lu 2007; Zhao 1998) and promoted media to deliver what appeals to the audience including reporting sensitive social issues, such as corruption and abuse of power (de Burgh 2003, Tong and Sparks 2009), the authority still keeps a tight control over the content and media are required to follow the party line (Rawnsley 2006; Tong 2009; Tong and Sparks 2009). It is often taken for granted that media are the 'throat and tongue' of the party. Thus, according to de Burgh (2003: 802), 'What the state is doing is maintaining control over major political issues, keeping ownership under its thumb, issuing codes of conduct, and holding censorship meetings while releasing - or subjecting - media operations to market risks and rewards'.

3.3 The Internet, however, is regarded as alternative media (Atton 2002; Couldry and Curran 2003), because it provides ordinary people, instead of just the powerful and the elite, the means and channels to publicise their concerns and voices. Thus, it is not surprising that Chinese netizens use the Internet to articulate their complaints and raise their opinions (Yang 2003). Esarey and Xiao (2008) and Zhou (2009) note that criticisms of the government are not rare in blogosphere in China. China has the largest Internet user population in the world - by mid-2010 it had reached 420 million (CNNIC 2009). The large number, together with the Internet's inherent property to support relative anonymity, makes it possible for the Internet users to form strong public opinions on particular issues online. This often forms spontaneous online activism/movement and draws attention of the authorities (Yang 2009a; 2009b), and in this way it 
3.4 Thus, like satire, the Internet in China can be seen as a site where resistance stories are made visible. The apparent affinity between the two perhaps explains why satire has thrived in the Chinese Internet space. Yang (2009) notes that the Chinese Internet is often a hilarious and delightful place where jokes, puns and parodies flourish; and according to $\mathrm{Li}$ (2010) and Zhang (2010) online parody has become a popular culture in China in the past few years. Drawing upon the insights of the previous satire studies as discussed in the last section, and through the lens of a recent Internet incident, this paper discusses what this culture reveals in terms of resistance and power.

\section{Research Methods}

4.1 The term 'Internet incident' is of Chinese origin which in general refers to influential and large-scale collective action on the Internet. It reflects spontaneous online activism and movement (Yang 2009a; 2009b). Because of their influence, Internet incidents generate a large amount of online blogs and posts, and media reports. This paper focuses on the 'very yellow and very violent' incident which took place in the late 2007 and early 2008. The term 'very yellow and very violent' and the incident will be explained in the next section.

4.2 The accounts of the incident made entries into three online encyclopaedias, Wikipedia, Baidu Encyclopaedia, and Interactive Encyclopaedia (the last two are developed and operated in China based on the Wikipedia model), which provided initial information for the research. Following the references provided in these entries, original web blogs and posts and newspaper reports were retrieved in November 2010. The newspaper reports again described the incident in detail, which offered further clues for web searches for relevant blogs and posts. At the same time, another step taken to collect data was searching for web pages containing the key words of the incident - very yellow and very violent - using two search engines: Google and Baidu. The latter is the dominant Chinese search engine. Because these words have been made popular and widely used on the Internet thanks to the incident, both searches produced a huge number of web pages: the Google search resulted in more than one million, while the Baidu one did more than ten million. Since it was impossible to check all those results and the most relevant ones are likely to appear first, the first fifty web pages from each search were checked. According to the Search Engine Watch (2007), search engines are likely to rank a web page based on the location and frequency of the keywords on the page. The closer to the top and the more frequently the keywords appear on the page, the higher it tends to be ranked by search engines. In this paper, the web pages on which the term very yellow and very violent' appears less frequently and more towards the bottom are therefore under-represented.

4.3 In sum, the data were collected from three sources: online encyclopaedias, online newspapers, and web searches. Altogether 55 blogs and discussion threads contributing to the incident, and 19 newspaper reports and commentaries, were gathered, which helped to reconstruct the incident as accurately as is possible.

\section{The 'Very Yellow and Very Violent' Incident}

5.1 On December 27th, 2007, the China Central Television Station (CCTV) broadcasted in its CCTV News a report titled: It is urgent to purify the Internet. It reported that with Internet video services increasing, a large number of obscene and violent videos were circulating online, which harmed children. The report called for policy makers to make relevant laws and regulations as soon as possible to purify the Internet. A 13-year-old primary school student was interviewed in the programme with her real name ZF. She stated in the interview: 'Last time I searched the Internet for information, suddenly a window popped up. It was very yellow and very violent. I closed it immediately'. 'Yellow' in Chinese has several meanings and in this context it is a euphemism for 'pornographic' or 'vulgar'.

5.2 Immediately after the CCTV News the discussion about the report started on MOP, one of the most popular online discussion forums in China. What prompted the discussion was the interview, especially the words 'very yellow and very violent' (VYVV) which share the same structure of MOP's famous promotion advertisement: 'very good and very powerful'. Thus, it may not be surprising then that the post which started the discussion was titled: This evening's CCTV News was very powerful. The post read: 'I was having dinner when she said "very yellow and very violent". I could not help but laughing - very yellow and very violent [is similar to] very good and very powerful. This little girl must be a mopper.' This post provoked the discussion about the truth of these words. In MOP participants' view, such 'mature' language could not be out of a thirteen years old girl. Furthermore, according to Internet users' experience, even if searching with a purpose, it would not be easy to find videos with both obscene and violence elements. Therefore it was their opinion that it must be the reporter who put the words into the girl's mouth.

5.3 The scepticism resulted in a call for 'human flesh search' about the student on January 1st, 2008 on MOP. The person made the call posted the video clip of the interview and stated:

My dear CCTV, please put more effort in faking news. ... The girl was very co-operative, but I am wondering: how could a webpage be obscene and violent at the same time? How could a little girl tell what is obscene and what is violent? ...

5.4 'Human flesh search' is a unique Internet phenomenon in China. It involves a large number of people collaborating in searching both online and offline, and exposing, all traceable (personal) information about one target person. Such search is commonly initiated on online discussion forums when the target person provokes public indignation. People conducting the research are commonly referred to collectively as 'Human Flesh Search Engines'. While it is ruthless and has ethical and legal implications (Cheung 2009), human-flesh search is effective in finding personal information. Thus, it is not surprising that on the first web-page of the discussion thread, the student's personal information, including the date of birth, her school, her performance at school, and even the hospital where she was born, were exposed.

5.5 At the same time, netizens started to satirise the event on the Internet. The early satire was a caricature, which was based on a screenshot capturing the moment when the subtitles 'very yellow and very violent' appearing on the lower left corner of the screen. To be exact, the caricature is a cartoon version of the screenshot, as Figure 1 clearly shows. 


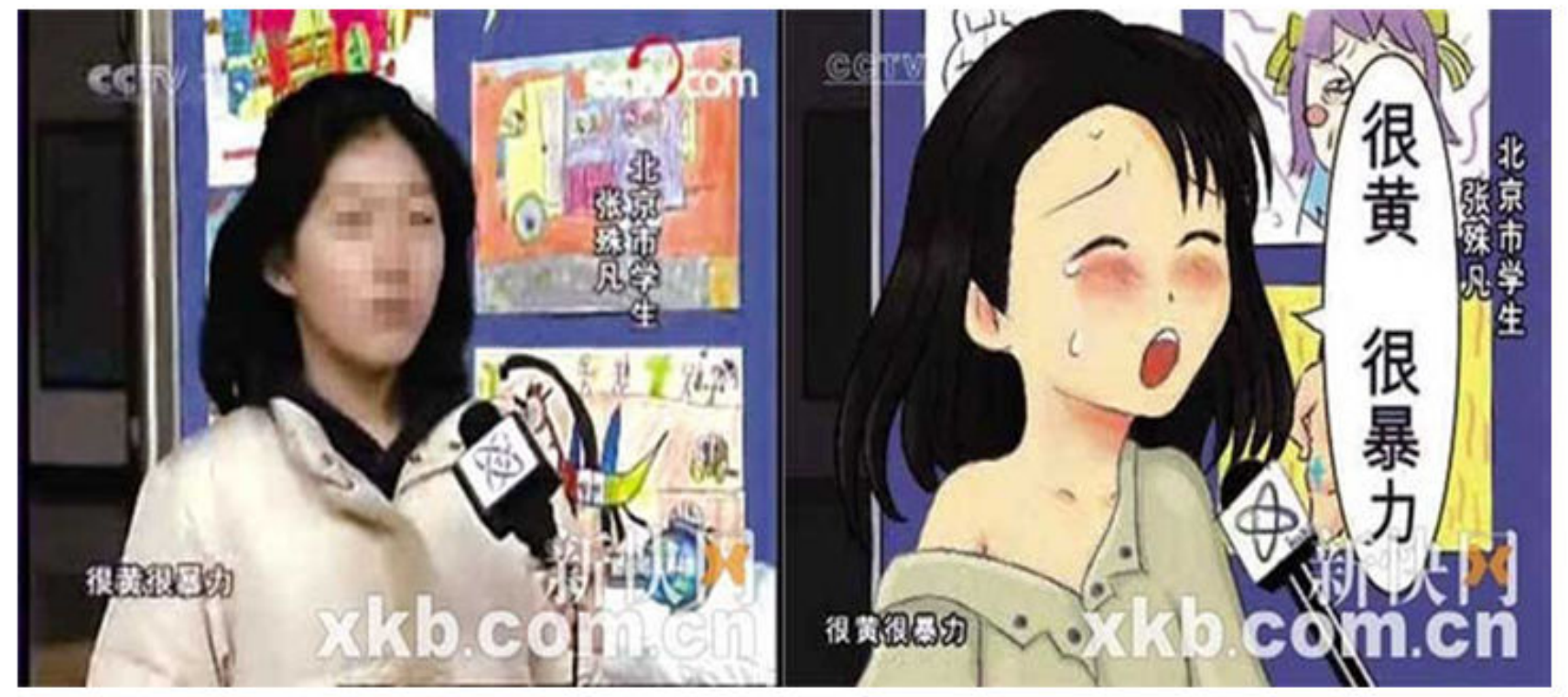

Figure 1: The screenshot and the caricature

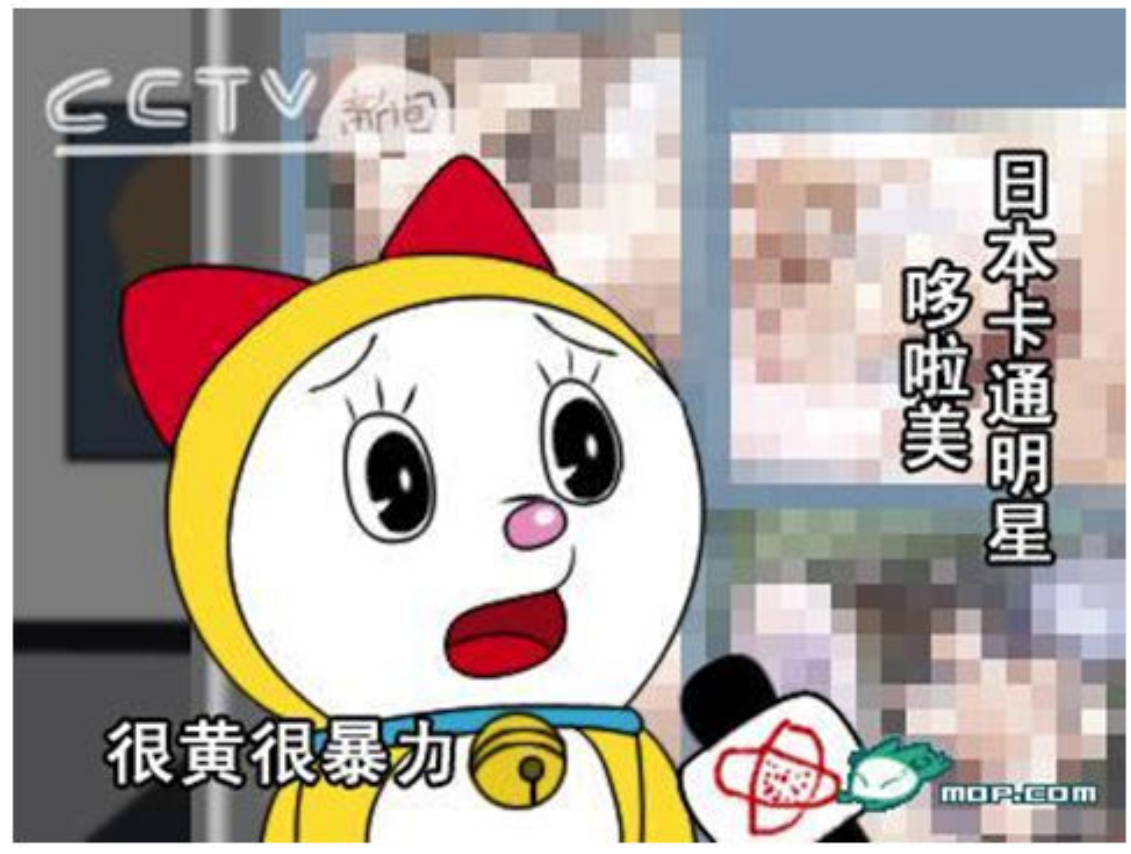

Figure 2: One imitation

5.6 The spread of this caricature online quickly inspired many imitations such as the one in Figure 2 . Furthermore, it also stimulated several 'mutated' forms of satirical work. One form displayed pictures that are both yellow and violent. Here, the double meanings of the word 'yellow' were humorously played with: pictures containing both yellow colour and violent elements were claimed to be 'VYVV' ones. In one such display, the author asked the question what the girl saw in the pop-up window and suggested twelve possible scenes. The first one is shown in Figure 3 and the author explained: The Simpsons are yellow and their skin colour is as yellow as oranges. They also seem violent: the father is strangling the son.' A second series of satirical VYVV pictures displayed eight sport pictures. Figure 4 shows one and the author explained that the 'yellow' footballers were so violent that they knocked over the referee. 


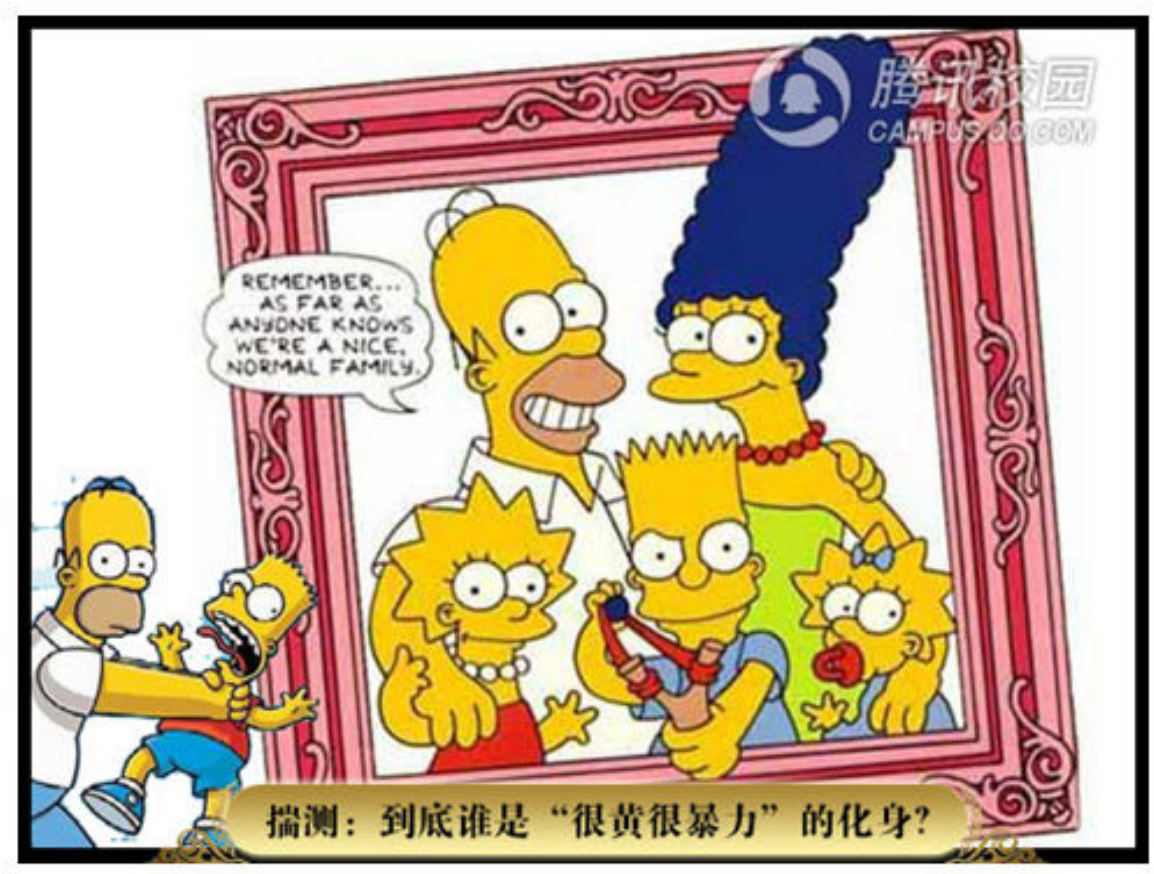

Figure 3: One of the twelve VYVV pictures

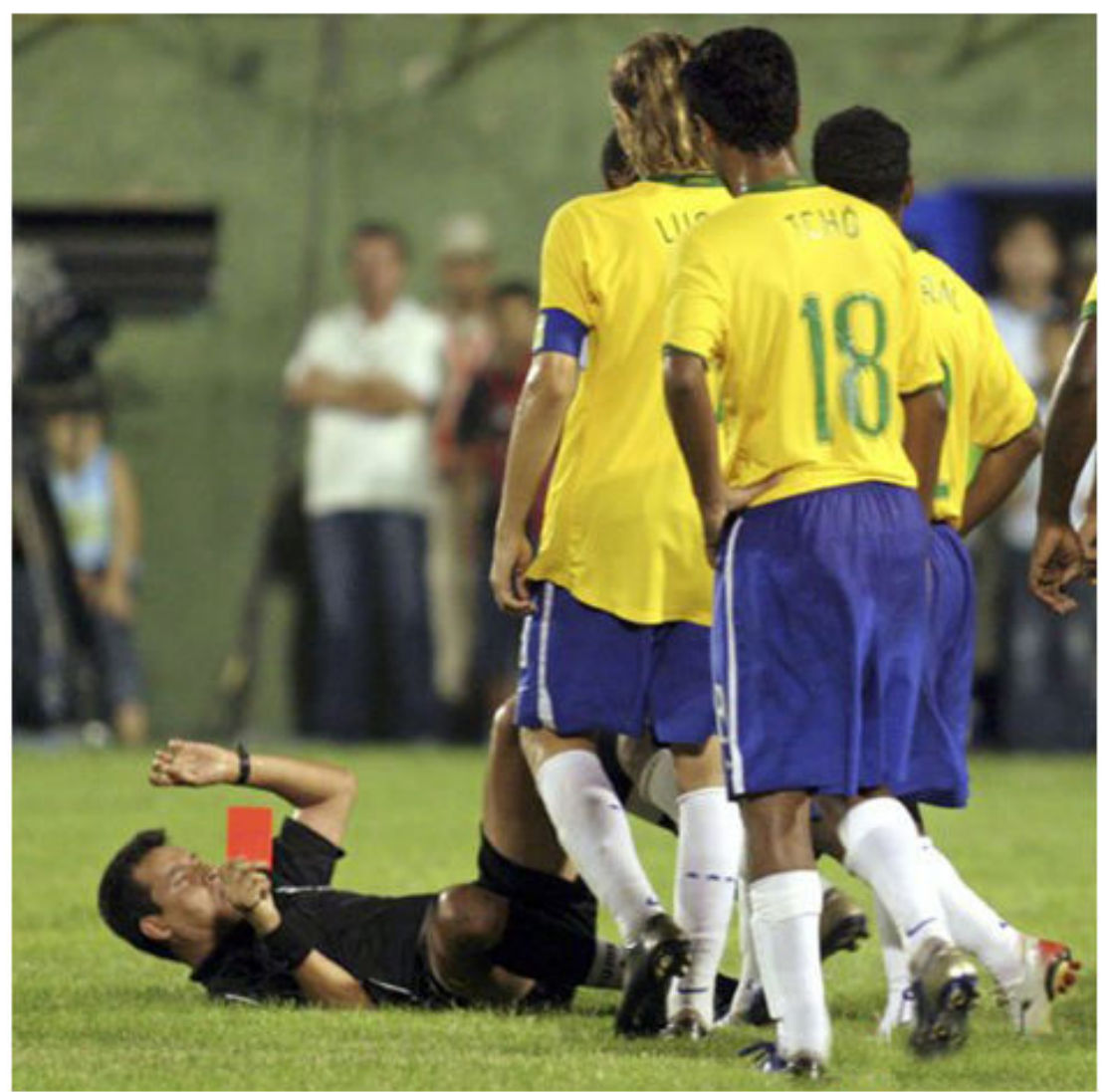

Figure 4: One of the eight VYVV sport pictures

5.7 Another form of satire is related to website. One blogger ranked the top ten VYVV websites. The term VYVV here was used as a synonym for 'obscene'. The blogger showed one CCTV webpage discussing obscenities such as male and female sexual organs. As a result, he/she ranked the CCTV website the No. 1 VYVV website and mocked, the webpage that the girl closed may be this one'. Another blogger created a website using hen.huang.hen.bao.li as its domain name (hen huang hen bao li is Chinese for VYVV). It asked netizens to submit VYVV - pornographic - images and materials and to vote for the most pornographic materials. 
5.8 The third form of satire is stories and jokes that make fun of the event. For example, mimicking biographies of historical figures, one blogger wrote a biography for the school girl in ancient Chinese prose with the title: History of New China - Biographies of Chaste Girls - The Biography of ZF. All these took place within half a month after the news report, and the short time span illustrated the intensive satirical attack over the event.

\section{Contextualising the incident}

6.1 Rather than viewing it as an isolated event, this incident needs to put into the context. CCTV is the state TV station and has the largest audience in China. This gives it immense influence, and yet also because of this, according to Zhang (2006), CCTV is more closely censored and has to follow the agenda set by the central government. As such, it functions primarily for propaganda purposes, and speaks on behalf of the government rather than the general public (Zhong 2004). This serves to alienate the ordinary people, which has produced, and accumulated overtime, resentment. The resentment was strongly expressed one year later when 22 Chinese intellectuals posted an open letter on the Internet on January 12th, 2009, which titled: Boycotting CCTV, Refusing Brainwash (for details, see Chen 2009). While in the past people voiced their discontents in everyday talk with their friends and colleagues, in the Internet era they could post the resentments online and discuss them with a large group of people.

6.2 The nature of the CCTV report mentioned above unfailingly drew netizens' attention to its propaganda function. The Internet, due to its openness, is believed to pose a threat to authoritarian regimes which depend very much on information control. As such, the Chinese authorities have been trying hard to control the Internet and to reduce the latter's influence (Chase and Mulvenon 2002; Kalathil and Boas 2003; Kluver and Banerjee 2005; Walton 2001; Weber and Lu 2007). One convenient excuse used by the authority is that the content of the Internet is vicious and therefore needs to be regulated (Li 2010). Netizens were of the opinion that CCTV was clearly communicating this message to the public in order to pave the way for regulating the Internet. One blogger wrote:

The real intention of the CCTV was not to criticise the content of the Internet: two days after the news report a new piece of Internet regulation was initiated. The regulation stipulates that the holding companies of the websites providing audio-visual services must be state-owned. .. This means that foreign audio-visual service websites can be legally blocked. (http://club3.kdnet.net/dispbbs. asp?boardid=1\&id=2024863)

6.3 Internet control and regulations that curtail freedom of information inevitably frustrate netizens and incur public resentment. This was clearly demonstrated one year later when Chinese netizens protested vehemently online against the authority's proposal to install a filtering software called the 'Green Dam' on every new computer to be sold in the country (for more details of the protest, see Watts and Branigan 2009).

6.4 The way in which the report was communicated further convinced netizens its propaganda nature. For them, the report was funny and yet detestable. It was funny because a primary school student spoke adult language. It was detestable because the reporter seemed to put these words into the student's mouth and to fake evidence for the purpose of propaganda. This suspected cheating behaviour prompted participants to vent suppressed anger at CCTV.

6.5 In this context, satire helped netizens to release their anger by launching a symbolic attack on CCTV. As Griffin (1994) points out, satire is 'rhetoric of inquiry and provocation'. Using satire, netizens raised the question: did the girl and thus the CCTV report tell the truth? They also explored the question by humorously speculating what the girl saw. The speculative answers as shown in Figure 3 and Figure 4 obviously were funny and ridiculed both the girl and CCTV. By raising and exploring the question it put the news report in the spotlight and made more and more people aware that both the report and the CCTV as the media source were suspect. This undoubtedly challenged and shamed CCTV and the authorities behind.

6.6 Once the focus is shifted onto the underlying power dynamics, however, the argument of Griffin (1994) looms large - satire reflects and reaffirms the powerless status of political underdogs. Netiznes clearly wanted CCTV to be punished for cheating the public. However, there was no independent media watchdog to which complaints could be made, and therefore formal investigation into the matter could not possibly be conducted. As such, netizens had no power to make CCTV accountable for its action. It is the authority that has this power. First and foremost, CCTV is owned and controlled by the state. Its management team is appointed by the Communist Party of China Central Committee (CPCCC). It is accountable to CPCCC and obliged to follow the party agenda and promote the image and policy of the state (Zhang 2006). According to Zhong (2004), it is the medium for the authority to inject messages to the mass. When the public interests and the official propaganda come into conflict, CCTV has to choose the latter at the cost of the former. In fact, it is so important to serve the propaganda purpose that CCTV may have to put professional integrity and ethics at risk and make up stories to show that state policies serve the 'public interest'. As to the ordinary Internet users' challenge, loud and noisy as it might be, it can be ignored. Thus, it is not surprising that during the incident, CCTV remained silent and was not bothered to provide any explanation. For netizens, it was frustrating when they suspected their interest being disserved but no one came out to explain the matter. In this situation, satirical attack seemed a good, or perhaps the only, option - though it hardly inflicted any real damage to the enemy, it nevertheless offered a sense of triumph and moral victory.

6.7 Such powerlessness is also reflected in the choice of the attack target: it was the schoolgirl who was at the forefront of the ridicule. Since it was the girl who said the catchphrase VYVV, it was natural to place her at the centre of the satire. However, she was just a child and netizens knew that such attack would negatively affect and change her life forever. This led to different opinions even among those who made the attack. One opinion was that since she was willing to be used for propaganda, the girl should be regarded as an accomplice and thus deserved to be ridiculed and humiliated. By contrast, another opinion held that it might be morally wrong to target a child. Thus, one blogger confessed later:

I felt the five words the girl said interesting, but had no issue with her. For her, 'very yellow and very violent' meant unhealthy web content. For me, it meant something else. [My intention of making and posting the satirical work was to] release my pent-up discontent [at CCTV] through her mouth.

6.8 This confession revealed the dilemma faced by many netizens: they did not want to harm a child, but there was no direct way to attack CCTV and to discharge their anger (for more details see http://news.qq.com/zt/2008/hh/). This confession also indicated that netizens were not heartless 
merrymakers. Their attack was not motivated by fun seeking, but by the disgust caused by CCTV. However, because no alternative avenue was available to challenge the latter, many of them opted for making the girl a scapegoat to achieve the end. This strategy served to reaffirm the underdog status of netizens: they could only attack weak scapegoats.

6.9 It has been noted that satire rarely changes power relations but serves to reaffirm the powerless status of the political underdogs (Elliot 1960; Griffin 1994; Speier 1998). This observation holds true in the VYVV incident. As Speier (1998: 1395) comments, The aggressive joke of the powerless is brutish and remorseless. But such jokes do not destroy power. Instead, they caricature power.' In fact, the powerlessness of the netizens foresaw that the satire would not disturb the status quo, since netizens were unable to make CCTV accountable.

6.10 This fate was further unveiled by the Google incident one and half years later. On June $18^{\text {th }} 2009$, CCTV used three prime time programmes, CCTV News, Topics in Focus, and News 1+1, bombarding criticism on Google for its search engine directing users to obscene materials. In the Topics in Focus programme, Gao Ye, a university student, was interviewed. He said that Google poisoned one of his classmates and made him restless by directing him to porn websites. At that time, the authority was pushing a new regulation requiring mandatory installation of the filtering software 'Green Dam'. The regulation, however, were not welcomed and sparked wide criticism because installation of the software would invade privacy and also cause technical problems. Many Internet users believed that following the official agenda, CCTV was trying to devise justification to enforce the regulation. As with the words VYVV which raised doubts, Gao Ye's words failed to convince the general public. On the 19th of June, motivated by suspicion, participants searched Gao Ye on Xiaonei Net (a Chinese website based on the Facebook model) and found him with his pictures. From the information he provided on the website, they noticed that he was actually an intern in the CCTV programme Topics in Focus. This indicated that CCTV was interviewing its own staff! This revelation provided Internet users with another good opportunity to voice their anger towards CCTV's propaganda and to expose its hypocrisy. This time, Gao Ye, for his word 'restless', was made the mocking target. Clearly the VYVV incident and the Google incident shared many similarities, which however indicated that no real impact on CCTV had been made.

6.11 Enough have been said about netizens' political powerlessness; their ability to produce and disseminate satire implies that the Internet brings about empowerment, at least at the symbolic level. Arguably, such satire would not possibly appear on other media, because first it is subversive and secondly it is from non-professionals. The Internet not only made grassroots satire possible, but more significantly it facilitated the spread. 'Spread' here has two layers of meanings. One is dissemination of an original work, and the other is spreading ideas, or metaphorically 'seeds', which can grow into various forms of satire. Thus, as shown in the last section, the VYVV satire consisted of several forms and genres. The nature of satire also contributed to the spread - satirical attack brought about pleasure, not only because it was cathartic, but also because it was amusing and thus entertaining. The amusement as well as anger motivated netizens to play with and display their wit over the issue. The grassroots participation in making fun of the event seemed to make it a public competition - participants competed with each other in producing the most amusing work. In this way, the Internet released, and perhaps more crucially stimulated, the huge amount of grassroots wit and wisdom used to be hidden or buried in the general public. The release served to make and shore up a 'virtual carnival' or rather, a spontaneous grassroots satire movement.

6.12 For CCTV and the authorities behind, the release opened up the Pandora's Box. It caught them up in the spotlight of carnival-like public ridicule for a sustained period of time. Even today, while the movement has faded away, its legacy remains. The term 'VYVV' has been made an idiom and widely used in China as a replacement for words such as 'pornographic', 'obscene', and 'lewd'. Since its website was ranked No. 1 VYVV site, CCTV was nicknamed CCAV on the Internet (AV insinuates both adult and artificial videos). 'CCAV' is also commonly used as the synonym of 'hypocritical'. Thus, the movement pushes the association between CCTV and fake news into everyday language, and brings it to the surface of public consciousness.

\section{Conclusion}

7.1 Satire 'speaks truth to power' (Boler, 2006). This statement reveals that satire is potentially 'a site of resistance' to power (Connery and Combe 1995). However, satire is likely to be an accommodating choice and weapon for political underdogs and bears no real bite, and as such gives away an inescapable sense of powerlessness (Griffin 1994; Speier 1998). In the context of China, the Internet might also be said to be a site of resistance, because it offers the powerless a medium for voice which is not controlled and dominated by the powerful. This affinity may explain the observation of several scholars (Li 2010; Yang 2009b; Zhang 2010) that satirical work is popular in the Chinese cyberspace. This popularity neither marks nor offers political power, but seems to correspond with and reflects a widespread feeling of being powerless.

7.2 Nevertheless, the popularity marks a strong symbolic resistance. The Internet has made satire a tool of grassroots, which facilitates the creation and spread of satirical ideas and work, and which helps to release and stimulate the enormous reserve of public wit and wisdom. As a result, satire on the Internet is no longer a one-off product, but has the potential to generate and prompt a chain of related satirical work within a short period of time, which in turn can create a satire movement spontaneously and subjects power to sustained shame and ridicule, though unable to destroy it. This indicates a shift of power dynamics at the symbolic level - used to be the recipient of messages from the authorities, the general public now have attained the weapon of online satire to employ symbolic power against the ruling elite. It is at this level that political underdogs have reasons to be optimistic; and it is at this level that the Internet makes a difference and can be said to be empowering.

\section{References}

ATTON, C. (2002) Alternative Media. London: Sage.

BERTHON, P.R., Pitt, L.F. and Campbell, C. (2008) 'Ad Lib: When Customers Create the Ad', California Management Review 50(4): 6-30.

BOLER, M. (2006) 'The Daily Show, Crossfire, and the Will to Truth', Scan Journal of Media Arts Culture 3(1) http://scan.net.au/scan/journal/display.php?journal_id=73

BOURDIEU, P. (1991) Language and Symbolic Power. Cambridge: Polity Press. 
CASTELLS, M. (2007) 'Communication, Power and Counter-Power in the Network Society', International Journal of Communication 1: 238-266.

CHASE, M.S. and Mulvenon, J.C. (2002) You've Got Dissent! Chinese Dissident Use of the Internet and Beijing's Counter-Strategies. <http://www.rand.org/pubs/monograph_reports/MR1543/index.html>

CHEN, S. (2009) 'China TV Faces Propaganda Charge', BBC News $<$ http://news.bbc.co.uk/1/hi/7824255.stm>

CHEUNG, A.S.Y (2009) 'China Internet Going Wild: Cyber-Hunting versus Privacy Protection', Computer Law \& Security Review 25; 275-279. [doi:10.1016/j.clsr.2009.03.007]

CONNERY, B.A. and Combe, K. (1995) 'Theorising Satire: A Retrospective and Introduction', in Connery, B.A. and Combe, K. (eds.) Theorizing Satire: Essays in Literary Criticism. New York: St. Martin's Press, pp. 1-15.

COULDRY, N. and Curran, J. (eds) (2003) Contesting Media Power: Alternative Media in a Networked World. Oxford: Rowman \& Littlefield.

DE BURGH, H. (2003) 'Kings without Crowns? The Re-Emergence of Investigative Journalism in China', Media, Culture \& Society 25(6): 801-820. [doi:10.1177/0163443703256005]

ELLIOTT, R.C. (1960) The Power of Satire: Magic, Ritual, Art. Princeton: Princeton University Press.

ESAREY, A. and Xiao Q. (2008) 'Political Expression in the Chinese Blogosphere: below the Radar', Asian Survey 48(5): 752-772. [doi:10.1525/AS.2008.48.5.752]

FLETCHER, M.D (1987) Contemporary Political Satire: Narrative Strategies in the Post-modern Context. London: University Press of America.

GRIFFIN, D. (1994) Satire: A Critical Reintroduction. Kentucky: The University Press of Kentucky.

KALATHIL, S. and Boas, T.C. (2003) Open Networks, Closed Regimes: The Impact of the Internet on Authoritarian Rule. <http://www.firstmonday.org/issues/issue8_1/kalathil/kalathil_chapter2.html>

KLUVER, R. and Banerjee, I. (2005) 'Political Culture, Regulation, and Democratization', Information, Communication \& Society 8(1): 30-46. [doi:10.1080/13691180500066847]

LEBOEUF, M. (2007) 'The Power of Ridicule: An Analysis of Satire', Senior Honors Projects, Paper 63. $<$ http://digitalcommons.uri.edu/cgi/viewcontent.cgi?article=1065\&context=srhonorsprog $>$

LI, H. (2010) 'Parody and Resistance on the Chinese Internet', Paper presented at the annual meeting of the International Communication Association, Suntec Singapore International Convention \& Exhibition Centre, Suntec City, Singapore, Jun 21, 2010.

LI, S. (2010) The Online Public Space and Popular Ethos in China', Media, Culture \& Society 32(1): 63-83. [doi:10.1177/0163443709350098]

MACKINNON, R. (2008) 'Flatter World and Thicker Walls? Blogs, Censorship and Civic Discourse in China', Public Choice 134: 31-46. [doi:10.1007/s11127-007-9199-0]

MEIKLE, G. (2008) 'Naming and Shaming: News Satire and Symbolic Power', The Electronic Journal of Communication 18(2, 3 \& 4) <http://www.cios.org/www/ejc/EJCPUBLIC/018/2/01847.html>

MENG, B. (2010) 'Moving Beyond Democratization: A Thought Piece on the China Internet Research Agenda', International Journal of Communication 4: 501-518. $<$ http://ijoc.org/ojs/index.php/ijoc/article/view/755/425>

OPEN NET INITIATIVE (2009) Internet Filtering in China. <http://opennet.net/sites/opennet.net/files/ONI_China_2009.pdf>

ORWELL, G. (1945) Funny, but not vulgar. <http://www.nonsenselit.org/Lear/essays/orwell_2.html>.

RAWNSLEY, G.D. (2006) 'The Media, Internet and Governance in China'. <http://ics.leeds.ac.uk/papers/gdr/exhibits/5/Media_and_governance_in_China.pdf>.

SHEN, F., Wang, N., Guo, Z. and Guo, L. (2009) 'Online Network Size, Efficacy, and Opinion Eexpression: Assessing the Impacts of Internet Use in China', International Journal of Public Opinion Research 21(4): 451-476. [doi:10.1093/ijpor/edp046]

SEARCH ENGINE WATCH (2007) 'How Search Engines Rank Web Pages'. <http://searchenginewatch.com/article/2064539/How-Search-Engines-Rank-Web-Pages>

SPEIER, H. (1998) 'Wit and Politics: An Essay on Laughter and Power', American Journal of Sociology 103(5): 1352-1401. [doi:10.1086/231355]

THOMPSON, J.B. (1995) The Media and Modernity: A Social Theory of the Media. Cambridge: Polity.

TONG, J. (2009) 'Press Self-Censorship in China: A Case Study in the Transformation of Discourse', Discourse and Society 20(5): 593-612. [doi:10.1177/0957926509106412]

TONG, J. and Sparks C. (2009) 'Investigative Journalism in China Today', Journalism Studies 10(3): 337352. [doi:10.1080/14616700802650830]

TSUI, L. (2003) 'The Panopticon as the Antithesis of a Space of Freedom: Control and Regulation of the Internet in China', China Information 17(2): 65-82. [doi:10.1177/0920203X0301700203]

WALTON, G. (2001) China's Golden Shield: Corporations and the Development of Surveillance Technology in the People's Republic of China. 
<http://www.ichrdd.ca/english/commdoc/publications/globalization/goldenShieldEng.html>.

WANG, S.S. and Hong, J. (2010) 'Discourse behind the Forbidden Realm: Internet Surveillance and Its Implications on China's Blogosphere', Telematics and Informatics 27(1): 67-78.

[doi:10.1016/j.tele.2009.03.004]

WANG, X. (2009) 'Seeking Channels for Engagement: Media Use and Political Communication by China's Rising Middle Class', China: An International Journal 7(1): 31-56.

WATTS, J. and Branigan, T. (2009) 'Chinese Delays Launch of Internet Filter Green Dam', Guardian, <http://www.guardian.co.uk/world/2009/jun/30/green-dam-china-delay>.

WEBER, I. and Lu J. (2007) 'Internet and Self-Regulation in China: The Cultural Logic of Controlled Commodification', Media, Culture \& Society 29(5): 772-789. [doi:10.1177/0163443707080536]

YANG, G. (2003) 'The Internet and Civil Society in China: A Preliminary Assessment', Journal of Contemporary China 12: 453-475. [doi:10.1080/10670560305471]

YANG, G. (2009a) 'Online Activism', J ournal of Democracy 20(3): 33-36.

YANG, G. (2009) The Power of the Internet in China: Citizen Activism Online. New York: Columbia University Press.

ZHANG, L. (2010) 'Carnival in Cyberspace: Egao as a Chinese Internet Subculture', Paper presented at the annual meeting of the International Communication Association, Suntec Singapore International Convention \& Exhibition Centre, Suntec City, Singapore, Jun 21, 2010.

ZHANG, X. (2006) 'Reading between the Headlines: SARS, Focus and TV Current Affairs Programmes in China', Media, Culture \& Society 28(5): 715-737. [doi:10.1177/0163443706067023]

ZHAO, Y. (1998) Media, Market, and Democracy in China: Between the Party Line and the Bottom Line. Urbana and Chicago: University of Illinois Press.

ZHONG, Y. (2004) 'CCTV Dialogue = Speaking + Listening: A Case Analysis of a Prestigious CCTV Talk Show Series Dialogue', Media, Culture \& Society 26(6): 821-840. [doi:10.1177/0163443704047028]

ZHOU, X (2009) The Political Blogosphere in China: A Content Analysis of the Blogs Regarding the Dismissal of Shanghai Leader Chen Liangyu', New Media \& Society 11(6): 1003-1022.

[doi:10.1177/1461444809336552] 